Original Research

\title{
Stromal cell-derived factor (SDF)-1 $a$ and platelet-rich plasma enhance bone regeneration and angiogenesis simultaneously in situ in rabbit calvaria
}

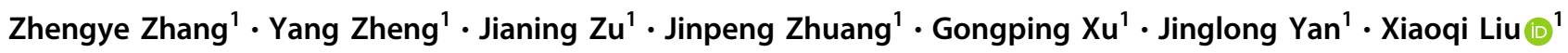

Received: 18 February 2020 / Accepted: 29 August 2021 / Published online: 15 September 2021

(c) The Author(s) 2021

\begin{abstract}
The current study aimed to evaluate the effects of chemokine stromal cell-derived factor (SDF)- $1 \alpha$ and platelet-rich plasma (PRP) on bone formation and angiogenesis, and to assess whether SDF- $1 \alpha$ and PRP could function synergistically. Four evenly distributed defects ( $8 \mathrm{~mm}$ in diameter) were generated in the calvarial bones of New Zealand white rabbits. All rabbits received four treatment regimens containing autogenous bone particles (AB), SDF- $1 \alpha$, or PRP. AB group presented significantly less bone formation compared with the other three groups 2 and 4 weeks after surgery. The amount of newly formed bone in the $\mathrm{AB}+\mathrm{PRP}+\mathrm{SDF}-1 \alpha$ group was similar to that in the $\mathrm{AB}+\mathrm{SDF}-1 \alpha$ group at the 4-week time-point $(p=$ $0.65)$, and was much greater than that in the $\mathrm{AB}$ and $\mathrm{AB}+\mathrm{PRP}$ group $(p<0.001)$. Meanwhile, more new blood vessels were formed in the $\mathrm{AB}+\mathrm{PRP}, \mathrm{AB}+\mathrm{SDF}-1 \alpha$, and $\mathrm{AB}+\mathrm{PRP}+\mathrm{SDF}-1 \alpha$ group versus the $\mathrm{AB}$ group. $\mathrm{AB}+\mathrm{PRP}+\mathrm{SDF}-1 \alpha$ group showed statistically increased angiogenesis compared with the $\mathrm{AB}+\mathrm{PRP}$ and $\mathrm{AB}+\mathrm{SDF}-1 \alpha$ groups (both $p<0.05$ ) after treatment for 2 and 4 weeks. These findings indicated that SDF-1 $\alpha$ and PRP might exhibit synergistic effects to promote angiogenesis in early bone regeneration.
\end{abstract}

These authors contributed equally: Zhengye Zhang, Yang Zheng

Supplementary information The online version contains supplementary material available at https://doi.org/10.1007/s10856021-06600-z.

Jinglong Yan

yanjlhyd@hotmail.com

$\triangle$ Xiaoqi Liu

liuxqhyd@hotmail.com
Department of Orthopedic Surgery, The Second Affiliated Hospital, Harbin Medical University, Harbin 150001, PR China 


\section{Graphical Abstract}

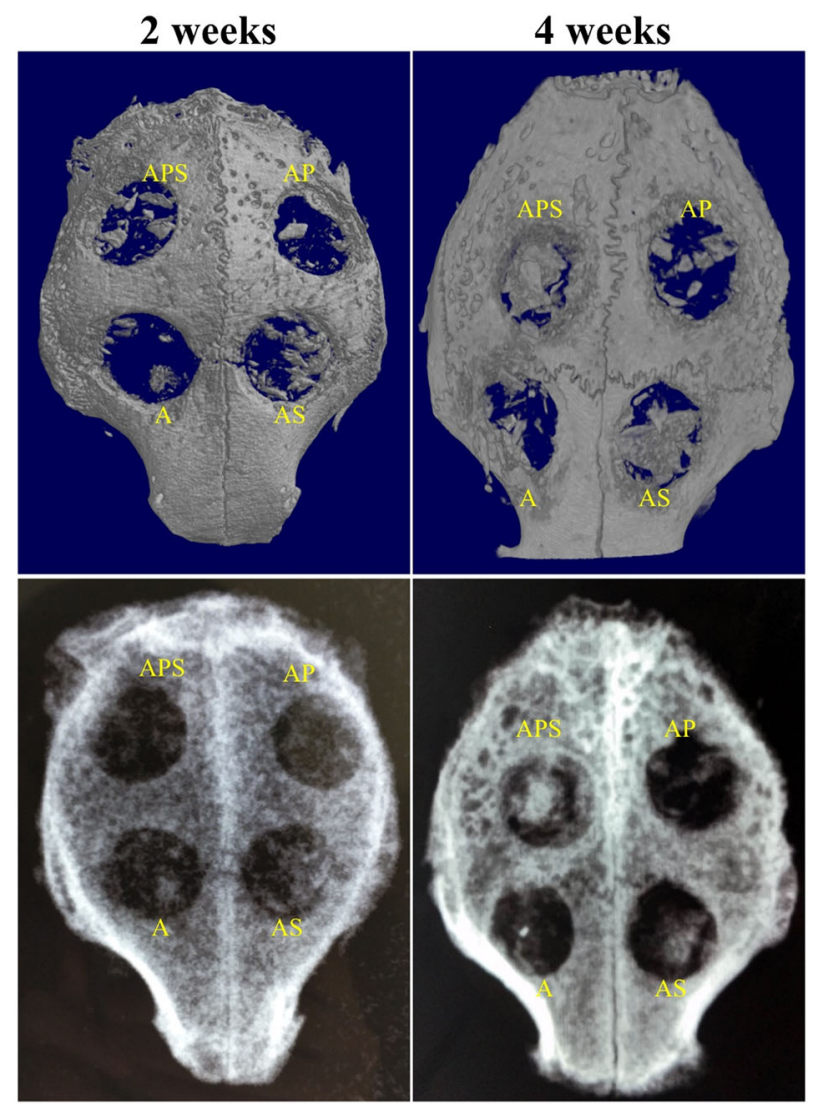

\section{Introduction}

Bone defects remain one of the most common clinical challenges around the world, which could be caused by tumor resection, trauma, or infection [1-3]. Conventional approaches in tissue engineering based on seeding of bone marrow mesenchymal stem cells (MSCs) have achieved successful effects [4-6]. However, host vascular system destruction and hematoma at the site of fracture may lead to death or functional deficits of the inoculated bone marrow MSCs.

SDF-1 $\alpha$ or CXCL12 represents a chemotactic protein, which interacts with G-protein-coupled receptors [7]. Although SDF- $1 \alpha$ is designated as a CXC chemokine, it is homologous to other CC and CXC chemokines, with $22 \%$ and $27 \%$ sequence similarity, respectively [8]. SDF- $1 \alpha$ is intrinsically linked to bone and cartilage physiologies. For instance, osteoblast cells secrete SDF- $1 \alpha$ upon induction by multiple cytokines such as interleukin-1 $\beta$ [9], tumor necrosis factor-alpha, and transforming growth factor- $\beta$ (TGF- $\beta$ ). Furthermore, articular chondrocytes express CXCR4 receptor and produce matrix metalloproteinases (MMP)-3, 9, and 13 in response to SDF-1 $\alpha$ secretion [10].
Notably, other chondrocyte populations, including epiphyseal hypertrophic chondrocytes, produce CXCR4 and MMP-13 [11].

In addition, the role of platelet-rich plasma (PRP) in bone repair remains controversial [12-15]. PRP may exert a beneficial effect on osseous regeneration [16]. Meanwhile, other studies reported that early and late bone healing processes were not enhanced by PRP [17-19]. PRP did not provide any statistically significant benefit in the management of rabbit mandibular defects [20]. Furthermore, high amount of PRP alone or in combination with bone graft particles can prevent the repair of noncritical defects in rabbit calvaria [21]. Therefore, we hypothesized that SDF- $1 \alpha$ and PRP could exert synergistic effects on angiogenesis.

\section{Materials and methods}

\subsection{Animals}

Sixteen 6-month-old New Zealand white rabbits weighing about $3 \mathrm{~kg}$ were used in the present study. All rabbits were treated humanely in accordance with The Code of Ethics of the World Medical Association for animal 
experiments (Revision of Directive 86/609/EEC). The study was approved by the ethics committee of our institution.

\subsection{Preparation of PRP and AB particles}

Prior to the induction of calvarial bone defects (CBD), $40 \mathrm{ml}$ blood was collected from each rabbit by cardiac puncture with citrate anticoagulation. Intravenous saline $(40 \mathrm{ml})$ injection was performed to maintain systemic blood volume.

Erythrocytes in whole blood sample were separated from leukocytes, platelets, and plasma by centrifugation at $1500 \mathrm{rpm}$ for $20 \mathrm{~min}$. The upper layer of the preparation contained platelets and leukocytes, while the lower layer comprised of red blood cells. All the supernatant and the upper 1 to $2 \mathrm{~mm}$ layer of erythrocytes were transferred into a new tube, and centrifuged at $3000 \mathrm{rpm}$ for $20 \mathrm{~min}$. Then the platelets, leukocytes, and the remaining erythrocytes were separated and precipitated from the plasma. Subsequently, approximately three quarters of the supernatant was discarded, and the remaining $0.18 \mathrm{ml}$ contained PRP. Whole blood and PRP preparations were diluted 1:100 in Brecher's solution for erythrocyte lysis. Then, the platelets in the diluted whole blood and PRP samples were assessed using a Neubauer chamber. All procedures were performed under sterile conditions [22]. The PRP preparation was inoculated into surgical defects after 45 min upon activation with calcium chloride $(0.5 \%$ final concentration). A bone mill was used to prepare $A B$ from calvarial bone during the creation of the surgical defects. Calvarial bone was grinded using a spherical grinding drill in saline. Particles of $210-270 \mu \mathrm{m}$ were isolated using a sub-sieve sizer and centrifuged at $120 \mathrm{rpm}$ for $5 \mathrm{~min}$. Approximately $0.2 \mathrm{ml}$ or $0.1 \mathrm{ml}$ of $\mathrm{AB}$ added with PRP preparation was immediately introduced into the surgical defects.

\subsection{Surgical procedure}

After the rabbits were anesthetized under aseptic conditions, semilunar scalp incisions were made on the anterior skull to ensure the removal of the full-thickness flaps in the posterior direction. While continuously irrigating with sterile saline, four skull CBD ( $8 \mathrm{~mm}$ in diameter) were generated with a trephine used in low-speed handpiece (Fig. 1) without damaging the dura, flushing the operative areas as described previously [23]. Four treatment regimens were administered to each rabbit: (1) autogenous bone particles alone (AB) (0.2 ml) (group A); (2) AB (0.2 ml)+PRP (AP group); (3) AB $(0.2 \mathrm{ml})+\mathrm{SDF}-1 \alpha$ (AS group); (4) AB $(0.1 \mathrm{ml})+\mathrm{PRP}+\mathrm{SDF}-$ $1 \alpha$ (APS group). Two 2005 micro-osmotic pumps (Durect, USA) were implanted into two of the four CBDs in the

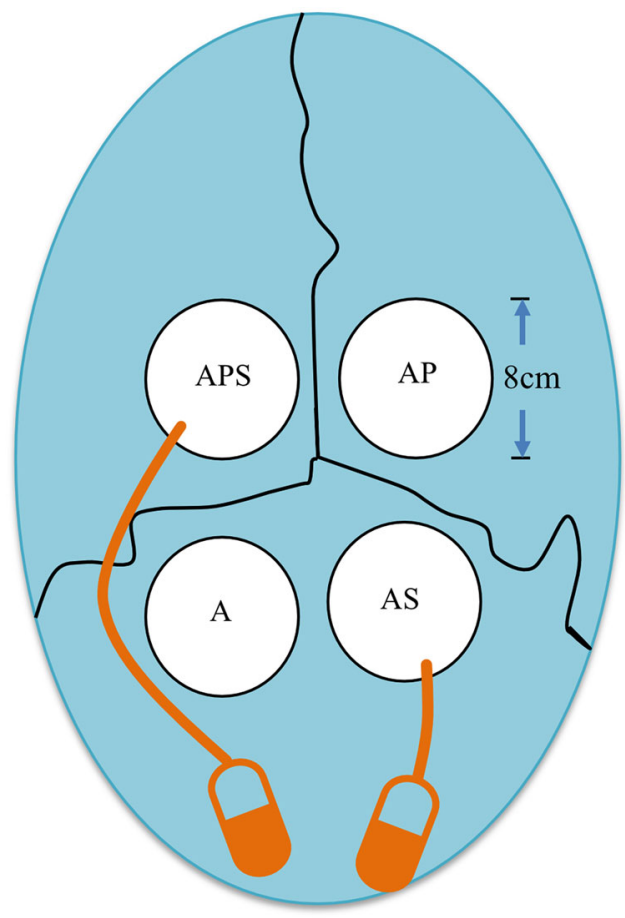

Fig. 1 Diagram showing the four evenly distributed surgical defects ( $8 \mathrm{~mm}$ diameter), allocated in the calvarial bones of each rabbit. A group, autogenous bone particles alone $(\mathrm{AB})$; AS group, $\mathrm{AB}+\mathrm{SDF}-$ $1 \alpha$; $\mathrm{AP}$ group, $\mathrm{AB}+\mathrm{PRP}$; APS group, $\mathrm{AB}+\mathrm{PRP}+\mathrm{SDF}-1 \alpha$. Orange pumps: two micro-osmotic pumps for loading recombinant human SDF-1 $\alpha$

calvaria of each rabbit. All rabbits were subjected to two osmotic pumps containing recombinant human SDF-1 $\alpha$ (PeproTech, USA) in PBS $(250 \mu \mathrm{g} / \mathrm{ml})$. The infusion amount of SDF-1 $\alpha$ in the AS and APS groups was $3.6 \mu \mathrm{g}$ per day, for a total of $25 \mu \mathrm{g}$. The osmotic pumps were placed on the inner skin of the head. After careful filling, the surgeons were blinded to the treatment regimens. Soft tissue was closed with interrupted sutures. Each rabbit was injected intramuscularly with 24,000 IU of penicillin G-benzathine for three consecutive days after the operation.

\subsection{Histological preparation}

At 2- and 4-week after surgery, an En bloc removal procedure was conducted on the initial defect areas and neighboring tissues. Head X-ray and micro-CT examinations were carried out. Calvarial specimens were fixed in $10 \%$ formalin for $24 \mathrm{~h}$ and decalcified in $10 \%$ ethylenediamine tetra acetic acid solution for 14 days. Then the specimens were divided into equal parts along the longitudinal direction, dehydrated by graded ethanol, cleared in xylene, and embedded in paraffin. A series of $5 \mu \mathrm{m}$ thick vertical sections were obtained from the middle of each defect and Masson's Trichrome staining was 
performed. The central portion of each defect was identified and subjected to histologic and histometric analysis. On average, three central sections were used for histologic evaluation, representing the central portion of the osteotomy defect.

\subsection{Radiographic analysis}

Rabbits underwent euthanasia by anesthetics overdose at 14 and 28 days after operation, respectively. The calvarium bone was then harvested, and fixed in $4 \%$ formalin for $48 \mathrm{~h}$. Standard anteroposterior radiographs were taken for bone formation assessment. A Micro-CT instrument (Scanco Medical, Switzerland) was utilized to examine the speci- mens (spatial resolution, $15 \mu \mathrm{m}$; 500 projections, $180^{\circ}$; aluminum filter, $1 \mathrm{~mm} ; 100 \mathrm{kV}, 100 \mathrm{~mA}$ ). Threedimensional image reconstruction was performed using the VGS Studio Max software. Image analysis was standardized according to the method reported by Jung et al. [23]. The formula was as follows: New bone area ratio (\%) $=$ Number of pixels of new bone area/Total number of pixels of the defect $\times 100 \%$.

\subsection{Immunohistochemistry}

Immunohistochemical analysis was conducted on the specimens with bone formation detected by histology. After incubating with the anti-CD34 primary antibody (Abcam, UK,
Fig. 2 Histological analysis of defects at 2 weeks (Masson's Trichrome staining). A group, autogenous bone particles alone (AB); AS group, $\mathrm{AB}+\mathrm{SDF}-1 \alpha$; $\mathrm{AP}$ group, $\mathrm{AB}+\mathrm{PRP}$; APS group, $\mathrm{AB}+\mathrm{PRP}+\mathrm{SDF}-1 \alpha$. Original magnification, $\times 100$. Arrow head, collagen fibers; arrow, new bone formation; swallow-tailed arrow, residual bone graft. Bar size, $200 \mu \mathrm{m}$
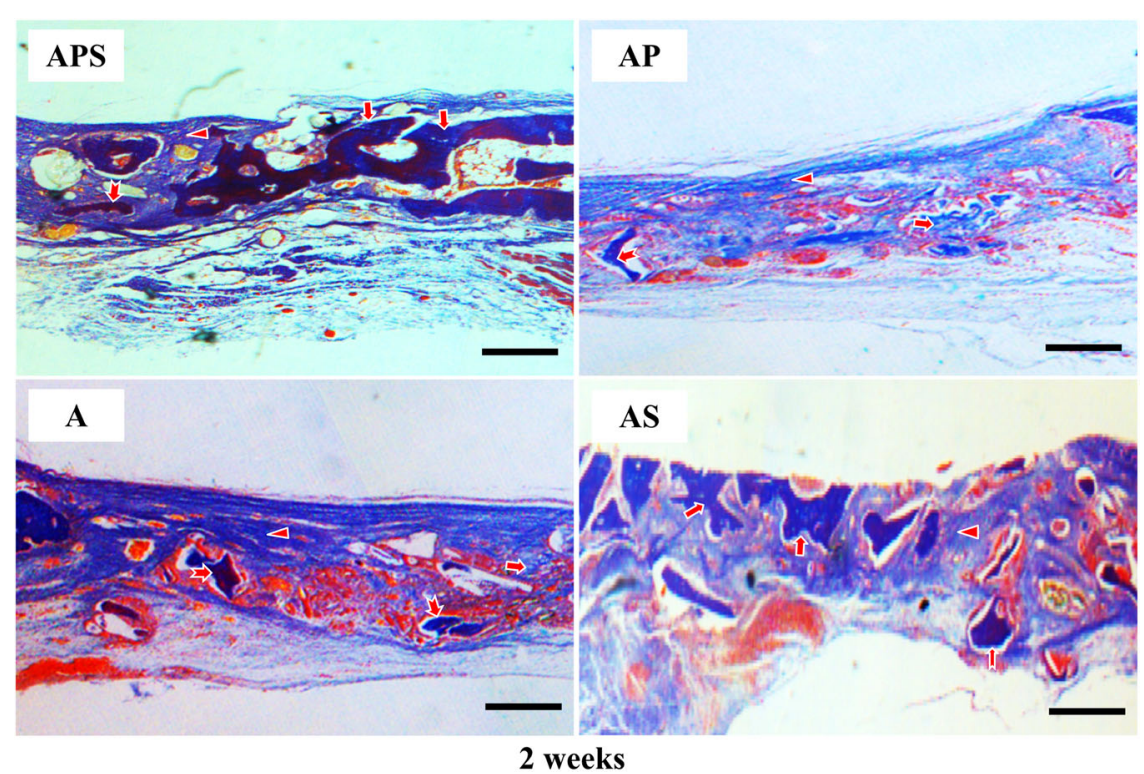

AS

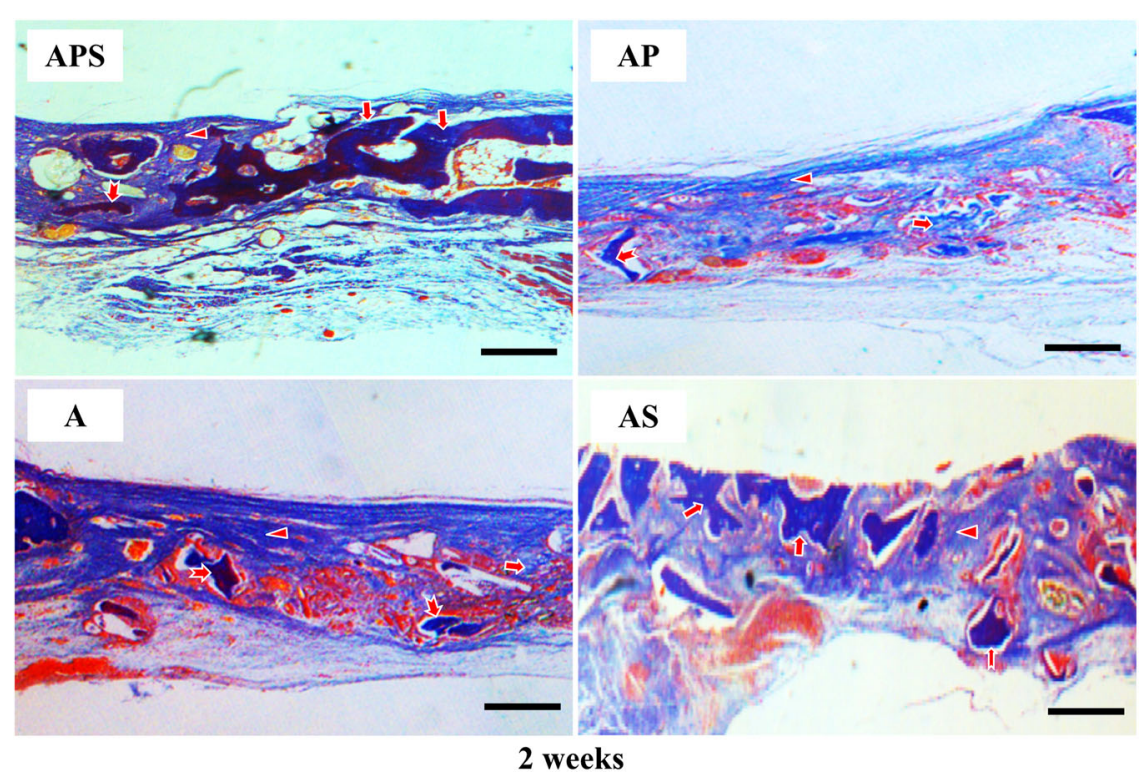

2 weeks

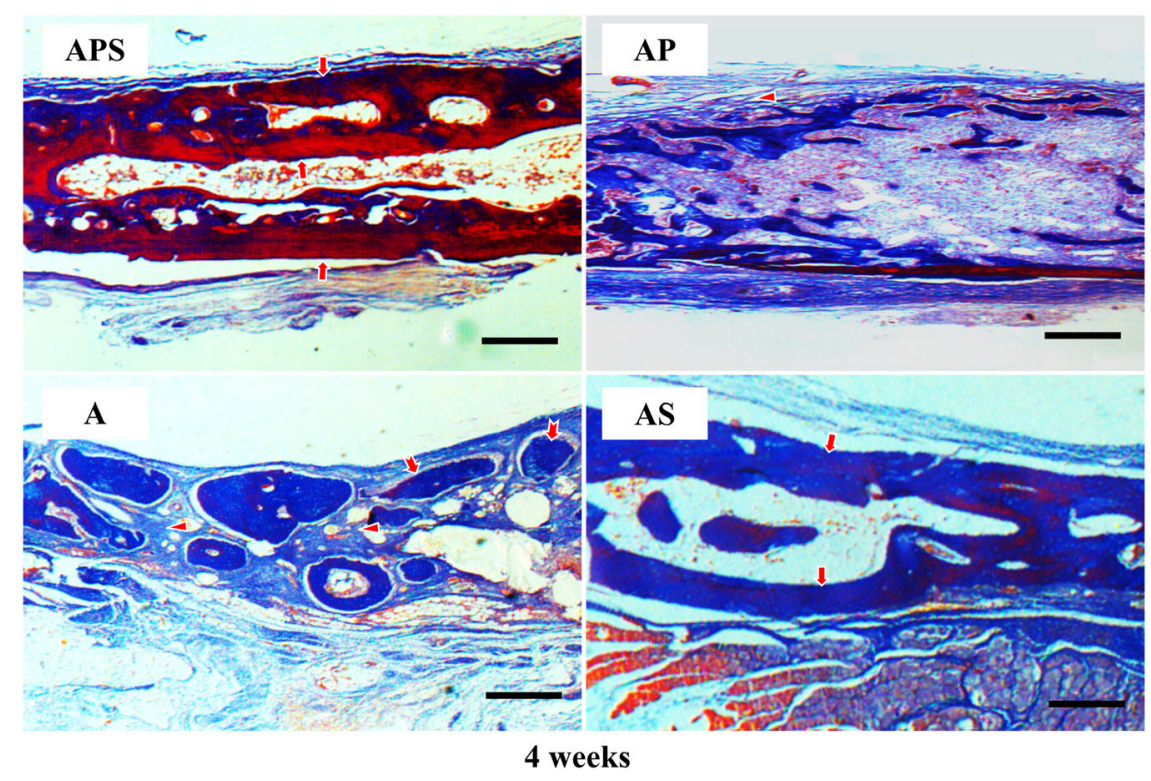

4 weeks
Fig. 3 Histological analysis of defects at 4 weeks (Masson's Trichrome staining). A group, autogenous bone particles alone (AB); AS group, $\mathrm{AB}+\mathrm{SDF}-1 \alpha$; $\mathrm{AP}$ group, $\mathrm{AB}+\mathrm{PRP}$; $\mathrm{APS}$ group, $\mathrm{AB}+\mathrm{PRP}+\mathrm{SDF}-1 \alpha$. Original magnification, $\times 100$. Arrow head, collagen fibers; arrow, new bone formation; swallow-tailed arrow, residual bone graft. Bar size, $200 \mu \mathrm{m}$ 
Fig. 4 A Immunohistochemical detection of $\mathrm{CD} 34$ revealing neovascularization in the A, AP, AS, and APS groups at 2 weeks. Original magnification, $\times 400$. Arrow, nascent blood vessels. Bar size, $50 \mu \mathrm{m}$. B Quantitative analysis of CD34-dependent the IPP software. $* p<0.05$, $* * p<0.01$ vessel density in four groups by

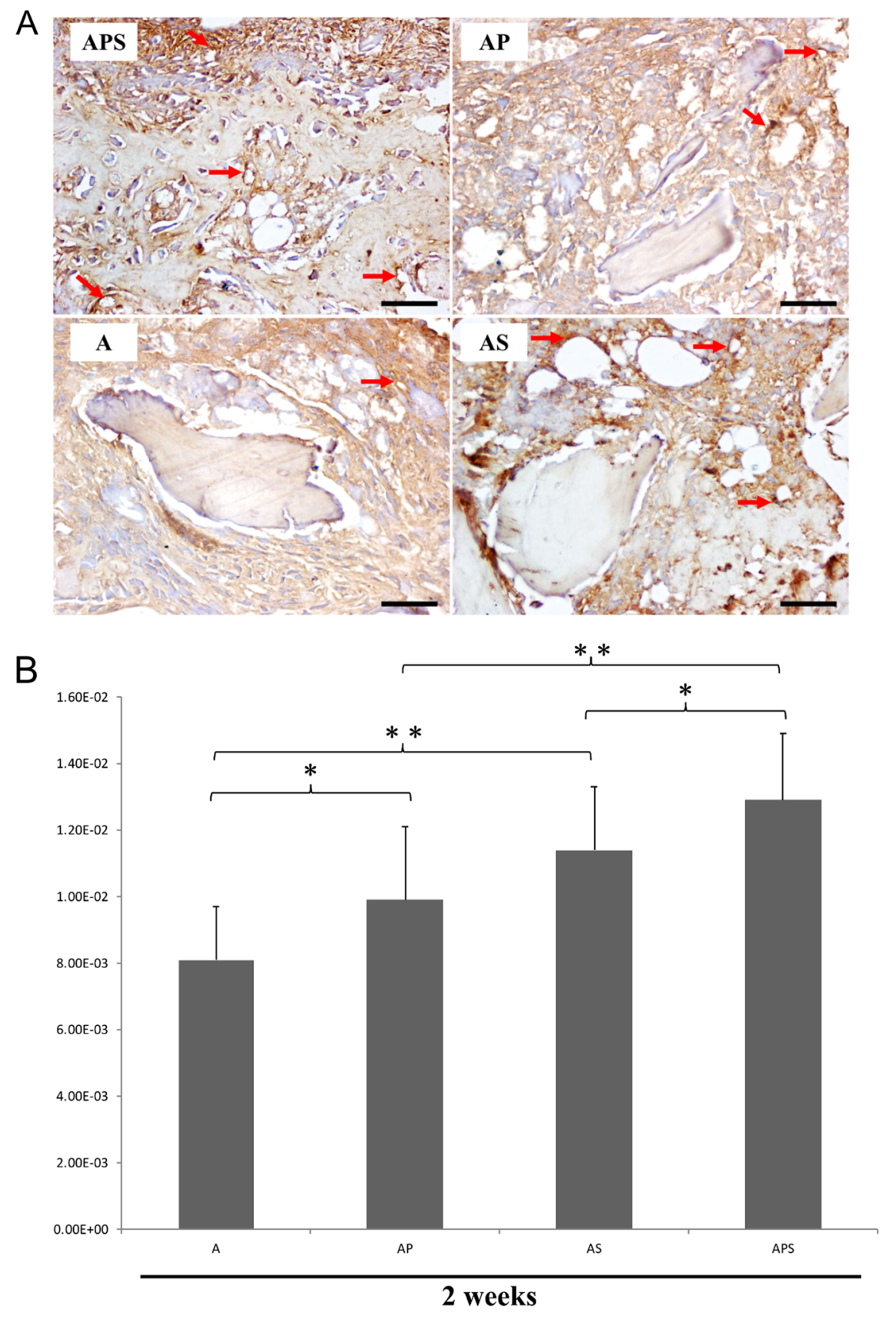

1:500), the secondary antibody was added. StreptABComplex/ HRP (Dako Corp., USA) was then employed to amplify the signals of cells labeled with diaminobenzidine (Dako, USA).

\subsection{Statistical analysis}

SPSS 18.0 (SPSS, USA) was used to perform the statistical analysis. The degree of bone formation and the number of blood vessels were determined in the previously defective area. The values were represented as mean \pm standard deviation. One-way analysis of variance with post hoc Tukey's test was adopted for comparisons. A $p$ value of $<0.05$ indicated statistical significance.

\section{Results}

\subsection{Platelet counts}

The platelet count in PRP preparation $(2264.19 \pm 372.52 \times$ $\left.10^{3} / \mu \mathrm{l}\right)$ was increased by 5.4 -fold compared to that in whole blood sample $\left(414.20 \pm 66.37 \times 10^{3} / \mu \mathrm{l}\right)$.

\subsection{Histological findings}

At 2-week postoperatively, the connective tissue containing collagen fibers entirely covered the defects in Group A. A limited number of new bone cells were found near the 
Table 1 New bone rates in defects

\begin{tabular}{lllll}
\hline & A & AP & AS & APS \\
\hline 2 weeks & & & & \\
$n$ & 8 & 8 & 8 & 8 \\
Mean (\%) & 5.77 & ${ }^{\mathrm{a}} 8.04$ & ${ }^{\mathrm{b}} 18.26$ & ${ }^{\mathrm{c}} 8.70$ \\
SD (\%) & 0.77 & 1.51 & 3.83 & 1.14 \\
4 weeks & & & & \\
$n$ & 8 & 8 & 8 & 8 \\
Mean $(\%)$ & 16.58 & $\mathrm{~d} 23.46$ & ${ }^{\mathrm{e}} 40.11$ & $\mathrm{f} 38.85$ \\
SD $(\%)$ & 3.76 & 4.63 & 6.26 & 6.85 \\
\hline
\end{tabular}

$\mathrm{A}=\mathrm{AB} ; \quad \mathrm{AP}=\mathrm{AB}+\mathrm{PRP} ; \quad \mathrm{AS}=\mathrm{AB}+\mathrm{SDF}-1 \alpha ; \quad \mathrm{APS}=\mathrm{AB}+\mathrm{PRP}$ $+\mathrm{SDF}-1 \alpha$

$A B$ autogenous bone particles alone, $P R P$ platelet-rich plasma, SDF- $1 \alpha$ stromal cell-derived factor- $1 \alpha$

2 weeks; ${ }^{\mathrm{a}}$ versus A $(p<0.05)$; ${ }^{\mathrm{b}}$ versus A, AP, and APS $(p<0.001)$; ${ }^{c}$ versus A $(p<0.05) ; 4$ weeks; ${ }^{\mathrm{d}}$ versus A $(p<0.05) ;{ }^{\mathrm{e}}$ versus A and AP $(p<0.001)$; ${ }^{\mathrm{f}}$ versus A and AP $(p<0.01)$; ${ }^{\mathrm{f}}$ versus AS $(p>0.05)$; $p<0.05$ indicated statistical significance

edge of the initial defect (Fig. 2), and most of the implanted bone particles were not resorbed (Supplementary Fig. 1). Furthermore, a small quantity of new bone was found close to the defect center 4 weeks after operation (Fig. 3). In a few samples, no new bone generation from bone graft particles was shown. A small number of newly formed blood vessels were observed in the tissue. In the AP group, all defective areas showed the presence of residual bone graft particles and multiple collagen fibers. At 2-week after surgery, nascent bone was found at the initial boundary and center of each defect (Fig. 2). A few small blood vessels were also observed at the edge of the defects (Fig. 4). After 4 weeks, abundant mineralized bone was found in the defect center (Fig. 3). Near-complete bone defect reconstruction was observed in 16 samples of the AS group after 2 and 4 weeks (Figs. 2 and 3). The AS group showed larger new bone areas in comparison with the other three groups. The area of nascent bone in the APS group was comparable to the AP group at 2-week, and similar to that in the APS group at 4-week postoperatively (Table 1). Neovascularization was prominent 2 weeks after operation (Fig. 4). In the AP and APS groups, the majority of bone graft particles regenerated nascent bone in their surroundings. Residual bone grafts were found throughout the entire defect in almost all AS group specimens after 2 and 4 weeks (Figs. 2 and 3). In the APS group, the majority of specimens resorbed large bone grafts after 4 weeks (Figs. 2 and 3, Supplementary Fig. 1).

At 2-week following surgery, blood vessel formation was less evident in group A. AS group showed almost two-fold increase in the number of vessels compared to group A. The number of nascent vessels in the APS group was higher than that in the AS and AP group (Figs. 4 and 5).

\subsection{Imaging analysis}

No inflammation and infection were detected in the collected samples. Bone formation was examined by microCT. At postoperative week 2, the area fraction of nascent bone in surgical defects was about $5.77 \pm 0.77 \%$ in the A group, $8.04 \pm 1.51 \%$ in the AP group, $18.26 \pm 3.83 \%$ in the AS group, and $8.70 \pm 1.14 \%$ in the APS group (Table $1)$. Bone formation significantly differed between $A$ and AP groups $(p=0.045)$. AS group showed markedly elevated bone generation compared with $\mathrm{A}$ and $\mathrm{AP}$ groups $(p$ $<0.001)$. AS and APS groups showed comparable osteogenesis values $(p=0.54)$ (Table 1$)$. At week 4 , the new bone area fraction in surgical defects were $16.58 \pm$ $3.76 \%$ in the A group, $23.46 \pm 4.63 \%$ in the AP group, $40.11 \pm 6.26 \%$ in the AS group, and $38.85 \pm 8.65 \%$ in the APS group (Table 1). No significant difference was observed between the AS and APS groups $(p=0.65)$, whereas there was a marked difference between the AP and APS groups $(p<0.001)$. It was noted that bone generation was centripetal, progressing from the edge toward the center.

\section{Discussion}

In this study, SDF-1 $\alpha$ was used to recruit autologous bone MSCs to defect areas for enhancing nascent bone formation. The application of SDF- $1 \alpha$ in tissue regeneration is hampered by its shortened half-life and timedependent delivery to the target injury sites. Therefore, a micro-osmotic pump was employed for continuous SDF$1 \alpha$ delivery and recruitment of progenitor cells. The results indicated increased bone generation in the AS group compared with A group at postoperative weeks 2 and $4(p<0.05)$.

It has been reported that the SDF- $1 \alpha-C X C R 4$ pathway might contribute to MSC recruitment to the injured tissue [24]. Meanwhile, increased autologous stem cell recruitment improves the tissue response and accelerates stem cell differentiation during the healing process [25]. In conjunction with previous data involving MSC recruitment and differentiation, an in situ regenerative medicine study based on targeted delivery of MSCs to degenerated tissue sites suggested that SDF- $1 \alpha$ was a promising therapeutic candidate [26].

We investigated the relationship between vessel density and new bone formation in all groups 2 weeks postoperatively. Abundant small blood vessels were observed in the newly reconstructed surgical defects 2 weeks after SDF$1 \alpha$ infusion. Interestingly, both SDF- $1 \alpha$ protein and gene delivered to ischemic tissues enhanced endothelial progenitor cell (EPC) recruitment to ischemic muscles, which 
Fig. 5 A Immunohistochemical detection of $\mathrm{CD} 34$ revealing neovascularization in the A, AP, AS, and APS groups at 4 weeks. Original magnification, $\times 400$. Arrow, nascent blood vessels. Bar size, $50 \mu \mathrm{m}$. B Quantitative analysis of CD34-dependent vessel density in four groups by the IPP software. $* p<0.05$, $* * p<0.01$, Supplementary Fig. 1. Anteroposterior radiographs showing the status of bone regeneration in the four groups. Left, 2 weeks postoperative. Right, 4 weeks postoperative. The upper section is CT 3D reconstruction images, and the lower section is $\mathrm{X}$-ray images

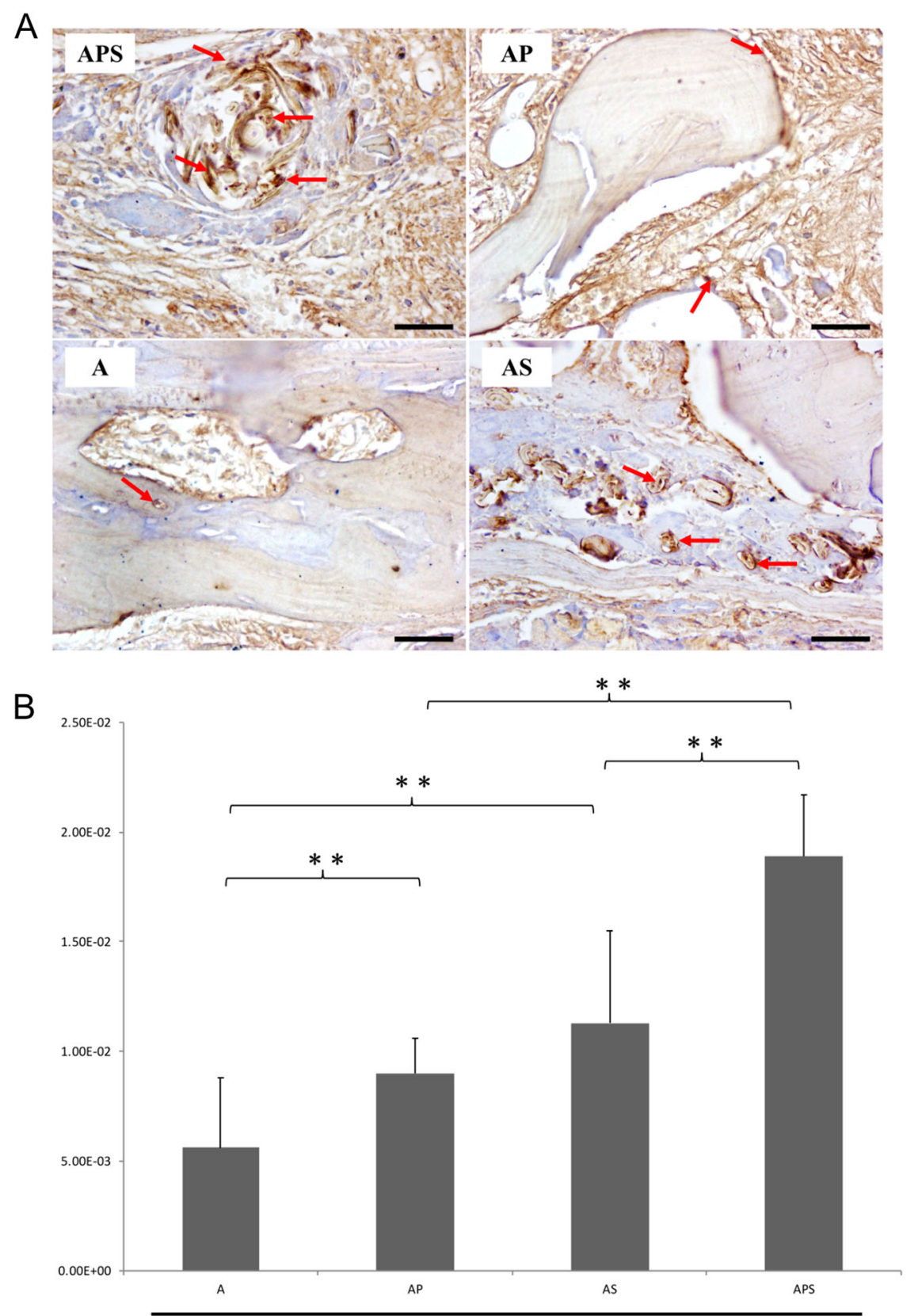

4 weeks in turn promoted angiogenesis [27-30]. In addition, cytokines that induce angiogenesis, including vascular endothelial growth factor (VEGF), fibroblast growth factor (FGF), and hepatocyte growth factor, are up-regulated by SDF-1 $\alpha$ [28, 29]. Increased VEGF induces or triggers angiogenic differentiation of stem cells, and even contributes to new vessel formation via mobilization of bone marrow-derived EPCs [31]. In this study, a significant difference in vessel density between SDF- $1 \alpha$-treatment and non-SDF- $1 \alpha$-treatment groups was found. SDF- $1 \alpha$ generated a pro-angiogenic environment to accelerate bone formation.
Meanwhile, PRP containing elevated amounts of growth factors (GFs) releases several GFs in the fracture rim, including platelet-derived growth factor (PDGF), TGF- $\beta$, FGF, and VEGF [32]. Previous reports demonstrated that TGF- $\beta$ and PDGF induce osteogenesis in animal models [33, 34], while VEGF enhances bone generation and healing by improving vessel formation [35]. Therefore, PRP supplementation is a promising candidate for bone healing.

Based on our results, the vessel density was different between the AS and APS groups. PRP had a positive effect on neovascularization. Combination of PRP with 
SDF- $1 \alpha$ resulted in increased angiogenesis and vertical bone augmentation [36] in rabbit calvaria. It significantly improved bone healing and bone formation [37, 38]. The effects may be attributed to the role of GFs released from the activated platelets. These GFs induced neovascularization and chemotaxis of tenocytes, and stimulated fibroblast and tenocyte proliferation, and collagen synthesis. Autologous PRP simultaneously increased the expression of several GFs and subsequently enhanced bone healing.

Overall, this study demonstrated that SDF- $1 \alpha$ potentially enhanced the area of newly formed bone within the engineered defects during the early stage of bone healing. Furthermore, application of SDF- $1 \alpha$ avoided several notable limitations in MSCs utilization. In contrast to exogenous MSCs, SDF- $1 \alpha$ is a promising candidate for in situ regenerative therapies. The combination of SDF$1 \alpha$ and PRP may have a synergistic effect on bone formation in surgically induced bone defects.

To the best of our knowledge, our study demonstrated the role of SDF- $1 \alpha$ in bone regeneration in vivo. However, the exact mechanism underlying bone regeneration by SDF- $1 \alpha$ was still unclear. Further studies are needed to clarify the mechanisms before clinical application.

\section{Conclusions}

Histologic and histomorphometric analyses after 2 and 4 weeks of treatment indicated that both SDF- $1 \alpha$ and PRP were promising candidates for accelerated bone regeneration. SDF- $1 \alpha$ combined with PRP showed synergistic effects on angiogenesis during the early phase of bone healing.

Funding The present work was funded by the Natural Science Foundation of Heilongjiang Province, China (Grant No. YQ2019H008), the Higher Education Reform Research Project of Heilongjiang Province (Grant Nos. SJGY20190429 and SJGY20190430), and Transverse Research Project from the Second Affiliated Hospital of Harbin Medical University (Grant Nos. 070500020146 and 070500020278 ), Standardized Training Project for Resident Doctors, the Second Affiliated Hospital of Harbin Medical University (Grant Nos. 2020020208 and 2020020223).

\section{Compliance with ethical standards}

Conflict of interest The authors declare no competing interests.

Ethics approval and consent to participate The study was approved by the Ethics Committee of the Second Affiliated Hospital, Harbin Medical University, Harbin.

Publisher's note Springer Nature remains neutral with regard to jurisdictional claims in published maps and institutional affiliations.
Open Access This article is licensed under a Creative Commons Attribution 4.0 International License, which permits use, sharing, adaptation, distribution and reproduction in any medium or format, as long as you give appropriate credit to the original author(s) and the source, provide a link to the Creative Commons license, and indicate if changes were made. The images or other third party material in this article are included in the article's Creative Commons license, unless indicated otherwise in a credit line to the material. If material is not included in the article's Creative Commons license and your intended use is not permitted by statutory regulation or exceeds the permitted use, you will need to obtain permission directly from the copyright holder. To view a copy of this license, visit http://creativecommons. org/licenses/by/4.0/.

\section{References}

1. Banwart JC, Asher MA, Hassanein RS. Iliac crest bone graft harvest donor site morbidity. A statistical evaluation. Spine (Phila Pa 1976). 1995;20:1055-60.

2. Kanakaris NK, Giannoudis PV. The health economics of the treatment of long-bone non-unions. Injury. 2007;38(Suppl 2): S77-84.

3. Sbordone L, Toti P, Menchini-Fabris G, Sbordone C, Guidetti F. Implant survival in maxillary and mandibular osseous onlay grafts and native bone: a 3-year clinical and computerized tomographic follow-up. Int J Oral Maxillofac Implants. 2009;24:695-703.

4. Awad HA, Zhang X, Reynolds DG, Guldberg RE, O'Keefe RJ, Schwarz EM. Recent advances in gene delivery for structural bone allografts. Tissue Eng. 2007;13:1973-85.

5. Castano-Izquierdo H, Alvarez-Barreto J, van den Dolder J, Jansen JA, Mikos AG, Sikavitsas VI. Pre-culture period of mesenchymal stem cells in osteogenic media influences their in vivo bone forming potential. J Biomed Mater Res A. 2007;82:129-38.

6. Ringe J, Strassburg S, Neumann K, Endres M, Notter M, Burmester GR, et al. Towards in situ tissue repair: human mesenchymal stem cells express chemokine receptors CXCR1, CXCR2 and CCR2, and migrate upon stimulation with CXCL8 but not CCL2. J Cell Biochem. 2007;101:135-46.

7. Bleul CC, Fuhlbrigge RC, Casasnovas JM, Aiuti A, Springer TA. A highly efficacious lymphocyte chemoattractant, stromal cellderived factor 1 (SDF-1). J Exp Med. 1996;184:1101-9.

8. Murphy PM, Baggiolini M, Charo IF, Hebert CA, Horuk R, Matsushima $\mathrm{K}$, et al. International union of pharmacology. XXII. Nomenclature for chemokine receptors. Pharmacol Rev. 2000;52:145-76.

9. Jung Y, Wang J, Schneider A, Sun YX, Koh-Paige AJ, Osman NI, et al. Regulation of SDF-1 (CXCL12) production by osteoblasts; a possible mechanism for stem cell homing. Bone. 2006;38:497-508.

10. Kanbe K, Takagishi K, Chen Q. Stimulation of matrix metalloprotease 3 release from human chondrocytes by the interaction of stromal cell-derived factor 1 and CXC chemokine receptor 4 . Arthritis Rheum. 2002;46:130-7.

11. Kanbe K, Takemura T, Takeuchi K, Chen Q, Takagishi K, Inoue K. Synovectomy reduces stromal-cell-derived factor-1 (SDF-1) which is involved in the destruction of cartilage in osteoarthritis and rheumatoid arthritis. J Bone Joint Surg Br. 2004;86:296-300.

12. Bahmanpour SP, Ghasemi MP, Sadeghi-Naini MM, Kashani IRP. Effects of platelet-rich plasma \& platelet-rich fibrin with and without stromal cell-derived factor-1 on repairing full-thickness cartilage defects in knees of rabbits. Iran $\mathrm{J}$ Med Sci. 2016;41:507-17.

13. Skwarcz S, Bryzek I, Gregosiewicz A, Warda E, Gaweda K, Tarczynska M, et al. Autologous activated platelet-rich plasma (PRP) in bone tissue healing — does it work? Assessment of PRP 
effect on bone defect healing in animal models. Pol J Vet Sci. 2019;22:109-15.

14. Oryan A, Alidadi S, Moshiri A. Platelet-rich plasma for bone healing and regeneration. Expert Opin Biol Ther. 2016;16:213-32.

15. Nagata MJ, Messora M, Pola N, Campos N, Vieira R, Esper LA, et al. Influence of the ratio of particulate autogenous bone graft/ platelet-rich plasma on bone healing in critical-size defects: a histologic and histometric study in rat calvaria. J Orthop Res. 2010;28:468-73.

16. Torres J, Tamimi FM, Tresguerres IF, Alkhraisat MH, Khraisat A, Lopez-Cabarcos E, et al. Effect of solely applied platelet-rich plasma on osseous regeneration compared to Bio-Oss: a morphometric and densitometric study on rabbit calvaria. Clin Implant Dent Relat Res. 2008;10:106-12.

17. Plachokova AS, van den Dolder J, Stoelinga PJ, Jansen JA. The bone regenerative effect of platelet-rich plasma in combination with an osteoconductive material in rat cranial defects. Clin Oral Implants Res. 2006;17:305-11.

18. Plachokova AS, van den Dolder J, Stoelinga PJ, Jansen JA. Early effect of platelet-rich plasma on bone healing in combination with an osteoconductive material in rat cranial defects. Clin Oral Implants Res. 2007;18:244-51.

19. Mooren RE, Dankers AC, Merkx MA, Bronkhorst EM, Jansen JA, Stoelinga PJ. The effect of platelet-rich plasma on early and late bone healing using a mixture of particulate autogenous cancellous bone and Bio-Oss: an experimental study in goats. Int $\mathbf{J}$ Oral Maxillofac Surg. 2010;39:371-8.

20. Miloro M, Haralson DJ, Desa V. Bone healing in a rabbit mandibular defect using platelet-rich plasma. J Oral Maxillofac Surg. 2010;68:1225-30.

21. Oliveira Filho MA, Nassif PA, Malafaia O, Ribas Filho JM, Ribas CA, Camacho AC, et al. Effects of a highly concentrated plateletrich plasma on the bone repair using non-critical defects in the calvaria of rabbits. Acta Cir Bras. 2010;25:28-33.

22. Marx RE, Carlson ER, Eichstaedt RM, Schimmele SR, Strauss JE, Georgeff KR. Platelet-rich plasma: growth factor enhancement for bone grafts. Oral Surg Oral Med Oral Pathol Oral Radiol Endod. 1998;85:638-46.

23. Jung RE, Schmoekel HG, Zwahlen R, Kokovic V, Hammerle CH, Weber FE. Platelet-rich plasma and fibrin as delivery systems for recombinant human bone morphogenetic protein-2. Clin Oral Implants Res. 2005;16:676-82.

24. Son BR, Marquez-Curtis LA, Kucia M, Wysoczynski M, Turner AR, Ratajczak $\mathrm{J}$, et al. Migration of bone marrow and cord blood mesenchymal stem cells in vitro is regulated by stromal-derived factor1-CXCR4 and hepatocyte growth factor-c-met axes and involves matrix metalloproteinases. Stem Cells. 2006;24:1254-64.

25. Thevenot PT, Nair AM, Shen J, Lotfi P, Ko CY, Tang L. The effect of incorporation of SDF-1alpha into PLGA scaffolds on stem cell recruitment and the inflammatory response. Biomaterials. 2010;31:3997-4008.
26. Stich S, Haag M, Haupl T, Sezer O, Notter M, Kaps C, et al. Gene expression profiling of human mesenchymal stem cells chemotactically induced with CXCL12. Cell Tissue Res. 2009;336:225-36.

27. Yamaguchi J, Kusano KF, Masuo O, Kawamoto A, Silver M, Murasawa S, et al. Stromal cell-derived factor-1 effects on ex vivo expanded endothelial progenitor cell recruitment for ischemic neovascularization. Circulation. 2003;107:1322-8.

28. Abbott JD, Huang Y, Liu D, Hickey R, Krause DS, Giordano FJ. Stromal cell-derived factor-1alpha plays a critical role in stem cell recruitment to the heart after myocardial infarction but is not sufficient to induce homing in the absence of injury. Circulation. 2004;110:3300-5.

29. De Falco E, Porcelli D, Torella AR, Straino S, Iachininoto MG, Orlandi A, et al. SDF-1 involvement in endothelial phenotype and ischemia-induced recruitment of bone marrow progenitor cells. Blood. 2004;104:3472-82.

30. Hiasa K, Ishibashi M, Ohtani K, Inoue S, Zhao Q, Kitamoto S, et al. Gene transfer of stromal cell-derived factor-1alpha enhances ischemic vasculogenesis and angiogenesis via vascular endothelial growth factor/endothelial nitric oxide synthase-related pathway: next-generation chemokine therapy for therapeutic neovascularization. Circulation. 2004;109:2454-61.

31. Asahara T, Takahashi T, Masuda H, Kalka C, Chen D, Iwaguro H, et al. VEGF contributes to postnatal neovascularization by mobilizing bone marrow-derived endothelial progenitor cells. Embo J. 1999;18:3964-72.

32. Schmitt JM, Hwang K, Winn SR, Hollinger JO. Bone morphogenetic proteins: an update on basic biology and clinical relevance. J Orthop Res. 1999;17:269-78.

33. Bostrom MP, Asnis P. Transforming growth factor beta in fracture repair. Clin Orthop Relat Res. 1998;355 Suppl:S124-31.

34. Lamerigts NM, Buma P, Aspenberg P, Schreurs BW, Slooff TJ. Role of growth factors in the incorporation of unloaded bone allografts in the goat. Clin Orthop Relat Res. 1999;368:260-70.

35. Peng H, Usas A, Olshanski A, Ho AM, Gearhart B, Cooper GM, et al. VEGF improves, whereas sFlt1 inhibits, BMP2-induced bone formation and bone healing through modulation of angiogenesis. J Bone Miner Res. 2005;20:2017-27.

36. Torres J, Tamimi F, Tresguerres IF, Alkhraisat MH, Khraisat A, Blanco L, et al. Effect of combining platelet-rich plasma with anorganic bovine bone on vertical bone regeneration: early healing assessment in rabbit calvariae. Int J Oral Maxillofac Implants. 2010;25:123-9.

37. Kasten P, Vogel J, Geiger F, Niemeyer P, Luginbuhl R, Szalay K. The effect of platelet-rich plasma on healing in critical-size longbone defects. Biomaterials. 2008;29:3983-92.

38. Nagata MJ, Melo LG, Messora MR, Bomfim SR, Fucini SE, Garcia VG, et al. Effect of platelet-rich plasma on bone healing of autogenous bone grafts in critical-size defects. J Clin Periodontol. 2009;36:775-83. 